\title{
FACTORS FOR AND AGAINST ESTABLISHING AND WORKING IN PRIVATE PRACTICE CORRELATED WITH WORK-RELATED BEHAVIOR AND EXPERIENCE PATTERNS OF GERMAN PHYSICIANS IN SCHLESWIG-HOLSTEIN: A 2-YEAR LONGITUDINAL STUDY
}

\author{
EDGAR VOLTMER ${ }^{1}$, CLAUDIA SPAHN ${ }^{2}$, and ERICA FRANK ${ }^{3}$ \\ ${ }^{1}$ Friedensau Adventist University, Möckern-Friedensau, Germany \\ Department of Health and Behavioral Sciences \\ ${ }^{2}$ Albert-Ludwigs-University Freiburg, Freiburg, Germany \\ Medical Faculty, Freiburg Institute of Musicians' Medicine \\ ${ }^{3}$ University of British Columbia, Vancouver, Canada \\ School of Population and Public Health
}

\begin{abstract}
Objectives: To identify factors in favor of or against establishing and working in private practice, to determine the quality of life and work-related behavior and experience patterns of German physicians working in private practice, and to analyze the correlation of those factors. Material and Methods: A representative sample of physicians in private practice in Schleswig-Holstein, Germany, was surveyed according to a 2-year longitudinal design (T1 - 2008, N = 549 and T2 - 2010, N = 414). The study included 22 items regarding the attractiveness of establishing and working in private practice, and the questionnaires: the Short Form-12 Health Survey (SF-12), and Work-related Behavior and Experience Pattern (Arbeitsbezogenes Verhaltens- und Erlebensmuster - AVEM). Results: Job satisfaction among those private practitioners decreased over time but their willingness to choose the profession once again remained unchanged. Patient care and the continuity of physician-patient relationship encouraged establishing and working in private practice; state regulation, financial risk, and administrative effort weighed against it. At both T1 and T2, physicians scored significantly lower for mental health than general population. About $20 \%$ of physicians showed a healthy behavior and experience pattern but $40 \%$ of them showed the pattern of reduced working motivation. About $20 \%$ of participants were at elevated risk for overexertion and for burnout. Physical and mental health as well as the total distribution of patterns did not change significantly during the 2-year observation period. Physicians at higher burnout risk rated tasks related to patient care considerably less positively than those with healthy pattern. Conclusions: In order to improve job satisfaction and quality of life, and to make private practice more attractive, those German physicians require a) improved legislation, b) educational programs that promote the attractiveness of private practice, and c) highly accessible counseling services for the prevention and treatment of stress, overexertion, and burnout. Int J Occup Med Environ Health 2017;30(3):485-498
\end{abstract}

Key words:

Quality of life, Job satisfaction, Mental health, Workplace, Physicians, Private practice

Received: August 21, 2015. Accepted: May 12, 2016.

Corresponding author: E. Voltmer, Friedensau Adventist University, Department of Health and Behavioral Sciences, An der Ihle 19, 39291 Friedensau, Germany (e-mail: edgar.voltmer@thh-friedensau.de). 


\section{INTRODUCTION}

In Germany, physicians in private practice are often the first point of contact for patients in the health care system. Unfortunately, the perceived attractiveness of establishing private practice has declined over the years, especially for primary care/general medicine practices and in rural areas [1,2]. As a result, problems in covering medical services in remote areas have been described [2,3] and the severity of this problem is expected to rise. A long series of healthcare legislation amendments aimed at reducing costs has increased physicians' financial pressure, their administrative workload, and their perception of restricted professional autonomy [4-7]. The literature describes extended working hours, financial risks, extensive administration, and weak infrastructure as reasons for the declining interest in establishing private practice in rural areas [8,9]. In a study among Swiss physicians, uncertain developments in health policy and low income were arguments against the establishment of family medicine practices whereas the diversity of work, the broad spectrum of patients, and continuity in the doctor-patient relationship were arguments in favor of this discipline [10]. A comparably thorough study has not been conducted in Germany. Furthermore, psychosocial stress needs to be addressed as a possible impeding factor.

There are only a few studies that have examined professional satisfaction and work-related stress in German physicians in private practice. Götz et al. [11] found that general practitioners in Germany $(\mathrm{N}=523)$ were least satisfied with respect to income, working hours and psychosocial stress. In a recent qualitative study of physicians in a hematology/oncology practice $(\mathrm{N}=52)$, dealing with administrative issues and a high number of patients were the most stressful aspects of their work life [12]. Applying the effort-reward model to primary care physicians in the United Kingdom (UK), the United States of America (USA) and Germany, Siegrist et al. [13] found workrelated stress levels to be highest in Germany and lowest in the UK. In a comparative study among Norwegian and German physicians in private practice, German physicians had a significantly lower job satisfaction and a lower perception of reward as compared to their Norwegian colleagues [14]. In a representative study of physicians in private practice in Schleswig-Holstein, Germany, only one-third of physicians reported high or very high general satisfaction with their job whereas $21 \%$ of them were at risk for overexertion and $22 \%$ for burnout [15].

This study aimed to identify the factors in favor of or against establishing and working in private practice as perceived by German physicians in private practice. In addition, the relationship of those factors to work-related behavior and experience patterns were analyzed in order to see if such patterns only affected individual mental health and well-being or if they were also relevant for patient care.

\section{MATERIAL AND METHODS}

\section{German medical education and health care system}

Medical education in Germany takes 6 years. About a half of the graduates finish their doctoral dissertation during the course of study, an independent process that is not mandatory for graduation and qualifies for the title of "Dr. med." After the course of study, graduates who want to work with patients usually begin to work as physicians in their chosen speciality in hospital and may qualify as specialists. Each speciality has its own postgraduate education program which averages for about 4 to 6 years, depending on the specialty. General medicine also requires a speciality training that includes rotations in surgery, internal medicine and private practice. The decision to establish private practice is usually made after having worked at least several years in the hospital setting.

The Federal Ministry of Health is responsible for the nationwide legislation and supervision of health care. The responsibility of the federal states lies mainly in the provision and supervision of inpatient care and public 
health services. Medical care in Germany is divided into an outpatient and an inpatient sector. It is different from many Western countries in which outpatient care (especially specialist care) is provided by physicians employed by hospitals whereas outpatient treatment in Germany is provided by physicians in private practice who refer patients to hospitals when ambulatory possibilities have been exhausted [16].

The remuneration of physicians in private practice is mainly based on a fee-for-service system and organized in 2 steps. The Associations of Statutory Health Insurance Physicians in the federal states of Germany receive a total payment from public health insurance funds which they distribute among their members, the physicians in private practice. About $90 \%$ of the German population have a statutory health insurance. Only a minority of physicians (about 6\%) in private practice solely treat patients who have a private insurance. Those physicians work independently of the Associations of Statutory Health Insurance Physicians. After a fixed budget with a point system $(1989,1993)$, and individual practice budgets (1997) [16,17], remuneration is now (since 2009) mainly based on standard service volumes. Transgression leads to deduction [18].

\section{SAMPLE DESCRIPTION}

Data (T1 - 2008 and T2 - 2010) was analyzed in a longitudinal design. At T1, a stratified, random sample of physicians was drawn from the Association of Statutory Health Insurance Physicians in Schleswig-Holstein. Out of a population of 3935 physicians, a sample of 900 was randomly selected. The sample was stratified by discipline (general practitioners, medical or surgical specialization). At T2, 770 participants who were still active were re-surveyed. The mailing included a business reply envelope. In both surveys, reminders were sent out after 4 and 8 weeks to non-responders. To ensure anonymity, a random bar code was used for identifying non-responders. The study was approved by the Ethical Committee of the Medical Faculty of the University of Freiburg.

\section{Basic demographic and employment characteristics of the study samples}

$\mathrm{T} 1$ and T2 response rates were 61\% (549/900) and $53.8 \%$ (414/770), respectively. Although there were no significant differences with respect to age or specialty between responders and non-responders, a higher percentage of female physicians participated in the study $(\mathrm{p}<0.01)$. However, the study population included almost two-thirds of male subjects (T1: $64 \%$ male vs. $36 \%$ female, T2: $60 \%$ male vs. $40 \%$ female; those numbers matched with the general statistics of physicians in private practice in total Germany at T2 with a proportion of $63 \%$ male physicians). Working hours remained stable at about $48 \mathrm{~h} /$ week and about 1100 patient contacts were reported per quarter (for further characteristics of the sample see the Table 1).

\section{Instruments}

In addition to demographic questions, job-related subjective perceptions were assessed by 3 items (job satisfaction: "How satisfied are you overall with your job?," fulfilled job expectations: "How much does your current job meet the expectations that you had when you started?" and willingness to study medicine again: "Would you choose to study medicine again today if you had the choice to do so?"). Response options were presented on a 5-point Likert scale.

For the perception of factors in favor of or against establishing and working in private practice we used the 22 items of the Swiss study [10]. They comprised a preselected number of relevant issues for the topic of establishing and working in private practice and allowed us to compare results internationally. After a general query ("which factors, from your perspective, account in favor of or against establishing and working in private practice") 
Table 1. Sample characteristics of German physicians in private practice in Schleswig-Holstein at T1 (study in 2008) and T2 (study in 2010)

\begin{tabular}{|c|c|c|}
\hline \multirow[b]{2}{*}{ Characteristics } & \multicolumn{2}{|c|}{ Respondents } \\
\hline & $\begin{array}{c}\mathrm{T} 1 \\
(\mathrm{~N}=546)\end{array}$ & $\begin{array}{c}\mathrm{T} 2 \\
(\mathrm{~N}=414)\end{array}$ \\
\hline Age [years] $(\mathrm{M} \pm \mathrm{SD})$ & $51.7 \pm 8.0$ & $53.70 \pm 7.3$ \\
\hline$<40$ years $[\%]$ & 6.4 & 1.7 \\
\hline $40-49$ years [\%] & 35.3 & 31.6 \\
\hline $50-59$ years $[\%]$ & 40.4 & 43.5 \\
\hline$\geq 60$ years $[\%]$ & 17.9 & 23.2 \\
\hline \multicolumn{3}{|l|}{ Gender $[\%]$} \\
\hline female & 36.0 & 40.0 \\
\hline male & 64.0 & 60.0 \\
\hline \multicolumn{3}{|l|}{ Specialty $[\%]$} \\
\hline general medicine & 34.6 & 35.5 \\
\hline medical & 34.2 & 35.5 \\
\hline surgical & 31.1 & 29.0 \\
\hline Working time $[\mathrm{h} /$ week] $(\mathrm{M} \pm \mathrm{SD})$ & $48.1 \pm 13.3$ & $47.80 \pm 12.2$ \\
\hline \multicolumn{3}{|l|}{ Working time [\%] } \\
\hline$<40 \mathrm{~h} /$ week & 19.4 & 19.8 \\
\hline $40-49 \mathrm{~h} /$ week & 27.1 & 25.1 \\
\hline $50-59 \mathrm{~h} /$ week & 29.0 & 27.5 \\
\hline$\geq 60 \mathrm{~h} /$ week & 24.5 & 27.5 \\
\hline Patients/quarter $[\mathrm{n}](\mathrm{M} \pm \mathrm{SD})$ & $1156.2 \pm 773.8$ & $1057.77 \pm 624.7$ \\
\hline$<500[\%]$ & 14.3 & 14.0 \\
\hline 500-999 [\%] & 24.3 & 27.1 \\
\hline $1000-1499[\%]$ & 35.7 & 32.6 \\
\hline $1500-1999[\%]$ & 13.3 & 9.7 \\
\hline$\geq 2000[\%]$ & 12.4 & 16.7 \\
\hline
\end{tabular}

M - mean; SD - standard deviation.

22 factors (e.g., development of health policy, long-term care for patients) were listed and rated on a 5-point Likert scale from 1 "for" to 5 "against." In the Swiss study, no reliability or validity scores were reported [10]. In our study, ratings of 1 and 2 were added and listed as "for" 3 as "neutral," 4 and 5 as "against" for the description of proportions (see Figure 1).

The factor analysis of the 22 items with varimax rotation (eigenvalue $>1$ ) revealed 5 factors (I. Patient care, II. Legislation and finances, III. Work-organization and -development, IV. Special stress factors (e.g., time, emotional, administration), V. Significance of primary care). All items except for "small working teams" were assigned to one factor. Cronbach's $\alpha$ for the items of factor I was 0.924 , factor II 0.848 , factor III 0.686 , factor IV 0.669 , factor $\mathrm{V}$ 0.602. All factors except for the first (which was skewed to the right) were normally distributed. For the analysis of differences between 


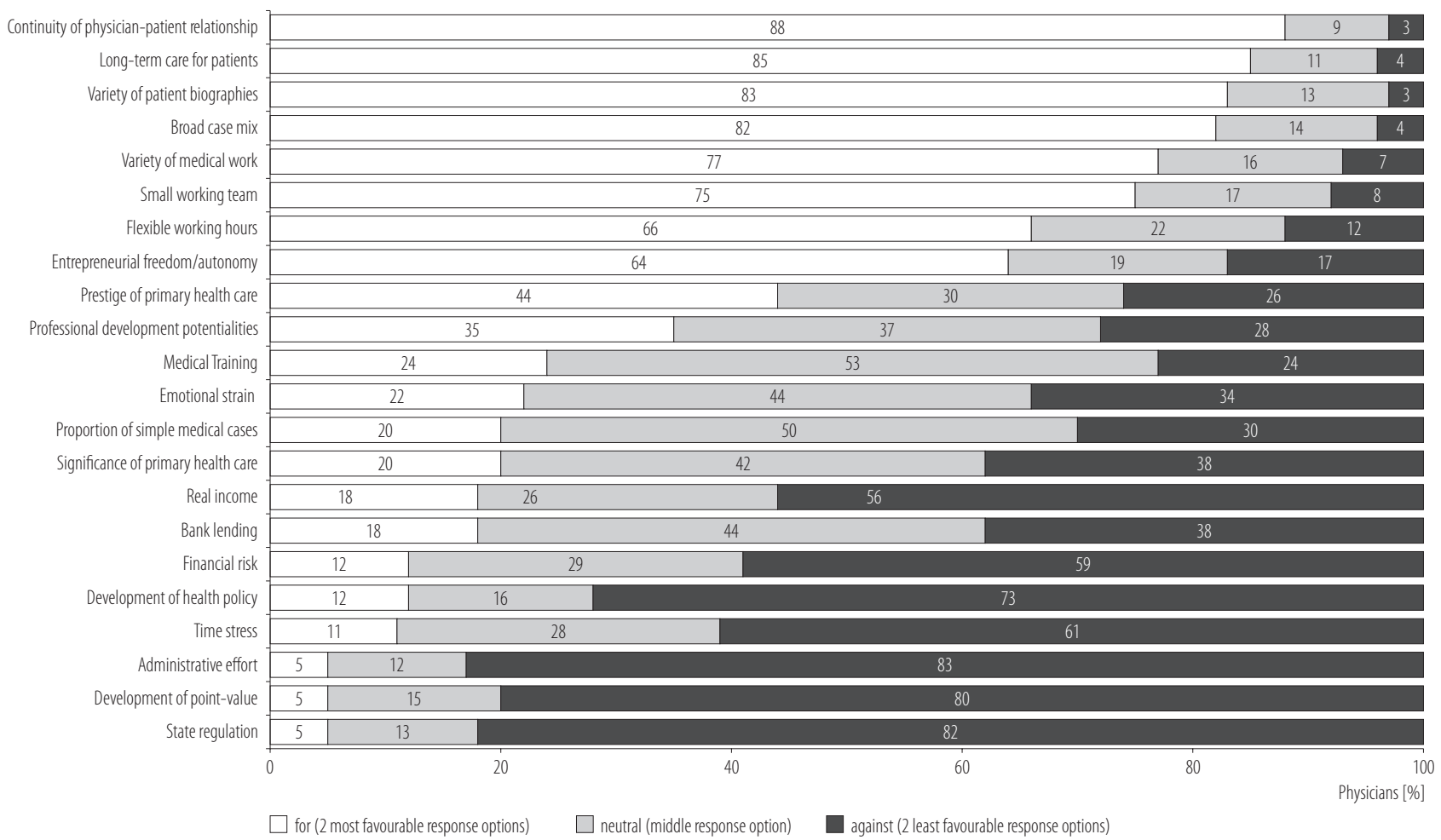

Fig. 1. Rating of the factors [10] in favor of or against establishing of private practice by German physicians in Schleswig-Holstein at T2 (study in 2010)

the 4 behavior and experience patterns in the perception of pro/con arguments regarding private practice we used primarily ANOVA. Although ANOVA is described as robust against violations of the normal distribution we also performed a Kruskal-Wallis Test with pairwise MannWhitney U post hoc test for the first factor; the results were similar.

\section{Short Form-12 Health Survey (SF-12)}

The SF-12 [19] is a short form developed from the original SF-36 Health Survey. The SF-36 comprises 8 scales (physical functioning, role limitations due to physical and emotional health problems, physical pain, general health perception, vitality, social functioning, and mental health). Cronbach's $\alpha$ of the subscales of the long form ranged between 0.57-0.94. Discriminant and convergent validity are well documented. A physical and mental health score could be calculated, which accounted for $80 \%$ to $85 \%$ of the reliable variance in the 8 SF-36 scales in both patient and general populations in the United States [19]. The SF-12 makes up one or 2 items of each of the original 8 scales. A summary score of physical and mental health is calculated with scoring algorithms for all items (the number of items in a survey is dependent on the number of dimensions for which scores are to be estimated - fewer questions are needed to calculate 2 summary scores than to calculate 8 scale scores [20]). A direct item - scale relation is no longer given. The calculated summary scores of the SF-12 account for more than $90 \%$ of the variance of the SF-36 results [19].

The SF-12 has proven to be a psychometrically robust and feasible instrument for the use in outcome evaluation of functional health in various countries and 
populations. Reference scores for various norm samples (sex, age, healthy, ill) are available. Higher scores represent higher physical or mental health. In a European validation study, mean scores for the physical health scale of the German sample $(\mathrm{N}=2453)$ were 49.6 (standard deviation $(\mathrm{SD})=8.7$ ) and for the mental health scale $52.3(\mathrm{SD}=8.0)[20,21]$. A cut-off score of 42 in mental health was used for detecting patients diagnosed with depressive disorder [22]. Cronbach's $\alpha$ scores in our sample were satisfactory with 0.74 for the physical health scale and 0.80 for the mental health scale.

\section{Work-related Behavior and Experience Pattern (AVEM)}

The Work-related Behavior and Experience Pattern (AVEM - Arbeitsbezogenes Verhaltens- und Erlebensmuster) [23] was developed to collect self-reported data about personal experiences of work-related stress and typical coping behavior.
The instrument covers the following 3 major domains (which are assessed by 11 separate scales):

- professional commitment,

- resistance towards stress,

- emotional well-being (in the context of work).

Each scale comprises 6 items with response options presented as the 5-point Likert-scale ranging from 1 "I strongly disagree" to 5 "I strongly agree." A cluster analysis of the initial AVEM sample group comprised 1598 representatives from various professions, revealed a 4-cluster solution (Figure 2). The same cluster solution was replicated with sufficient concurrence in 10 random samples drawn from the same 1598 test subjects (average $\kappa>0.80$ ). Scale reliability was assessed for samples of various professions. The median Cronbach's $\alpha$ was 0.81 (minimum: 0.79, maximum: 0.86). The 4 different types of work-related experience and behavior patterns derived from the cluster analysis are described as follows.

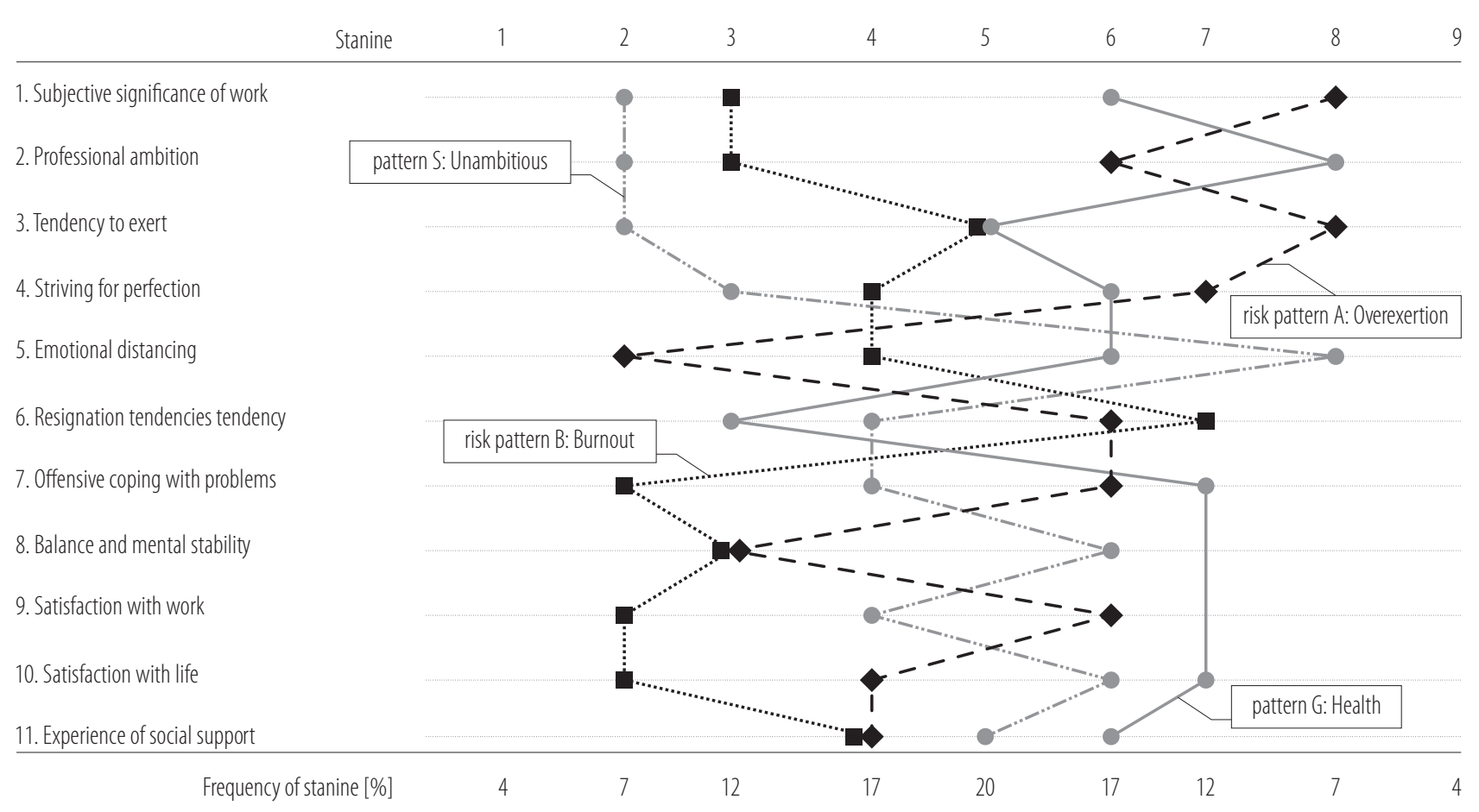

The 11 dimensions may be divided into 3 domains: professional commitment (1-5), resistance towards stress (6-8), and emotional well-being (9-11).

Fig. 2. Dimensions related to 4 patterns of the Work-related Behavior and Experience Pattern questionnaire [23] 


\section{Pattern G: Health}

This pattern represents a healthy attitude towards work. The individuals are ambitious at work but are also able to maintain emotional distance from work. They score high in those dimensions that represent resistance to stress and in all the dimensions related to positive emotions.

\section{Pattern S: Unambitious}

A rather unambitious attitude towards work characterizes this pattern. The lowest scores were achieved in the dimensions describing commitment to work and the highest scores - in capacity for detachment. Nevertheless, depending on the scores on tendency to resignation and inner balance, satisfaction with life, and the experience of social support, this pattern bears a certain ambivalence. The reduced working motivation could be a sign of less interest in work than in other areas of life, or a sign of inner frustration with work.

In contrast to patterns $\mathrm{G}$ and $\mathrm{S}$, the following 2 patterns are repeatedly shown to be linked to illness. Therefore, they play a key role in preventing impairment and promoting health.

\section{Risk pattern A: Overexertion}

This pattern is characterized by an excessive commitment to work and difficulties with emotional distancing from work. Limited coping abilities in stressful situations and negative emotions also characterize this exhausting pattern. Individuals with risk pattern A show many similarities to the concept of type-A behavior described for coronary artery disease and myocardial infarction [24].

\section{Risk pattern B: Burnout}

Individuals with this pattern show low scores on the dimensions related to professional commitment. They attain high scores on tendencies to resignation and correspondingly low scores on emotional distancing and active coping. Their emotional status is characterized by low scores on balance and mental stability, satisfaction with work, and satisfaction with life, and they show limited experience of social support. This pattern represents the core symptoms of burnout [23]. The validity of the instrument was supported by moderate to good correlations with scales that measured related constructs (e.g., Freiburg Personal Inventory (FPI), Maslach Burnout Inventory (MBI), Big-Five Adjective List) [23]. All patterns differed significantly in psychological complaints, with risk pattern B showing the lowest scores of self-esteem and perceived performance and highest scores of exhaustion. The health relevance of the patterns was supported by significant correlations with a broad set of criteria such as emotional stability (measured with FPI), mental and physical condition (Gießen Test, Berlin Procedure for the Neurosis Diagnostics (Berliner Verfahren zur Neurosendiagnostik - BVND)), sickness-related absence, blood pressure, heart rate, type-A-behavior (Questionnaire Analyses of Stress Relevant Coping - FABA), and burnout (MBI) [23]. Cronbach's $\alpha$ scores for the 11 dimensions in our sample were satisfactorily ranging from 0.77 to 0.88 at $\mathrm{T} 1$ and from 0.75 to 0.87 at $\mathrm{T} 2$.

\section{Statistics}

Analyses were conducted by means of SPSS software for Windows v. 15.0 (SPSS Inc., USA). We reported univariate statistics as means and standard deviations for continuous variables and percentages for categorical variables. Associations between categorical variables were analyzed using $\mathrm{Chi}^{2}$ tests (cross sectional comparison of the behavior and experience patterns of the whole study samples at T1 and T2). With respect to continuous variables, data was analyzed using 2 tailed t-tests and analysis of variance in a general linear model. For the latter we used partial eta ${ }^{2}$ as a measure for the effect size. Regarding the longitudinal comparison of the distribution of behavior and experience patterns of those that had answered 
at $\mathrm{T} 1$ and $\mathrm{T} 2$, the nonparametric test for linked samples was employed (McNemar-Bowker).

\section{RESULTS}

\section{Arguments in favor of or against}

\section{establishing private practice}

At T2, $77 \%$ to $88 \%$ of the respondents agreed with the 2 most favorable response options that a broad variety of medical tasks, a good case mix, and long-term relationships with patients were the main arguments in favor of establishing a private practice (Figure 1). Additional positive factors were small working teams, flexible working hours, and entrepreneurial freedom. Factors that negatively influence the establishment of a private practice with $\geq 80 \%$ agreement by respondents (the 2 least favorable response options) were state regulation, development of point-value, and administrative tasks. The importance of primary care in medical education and training, the emotional strain and the proportion of misdemeanor cases were judged neither in favor nor against the establishment of private practice. There were no significant differences between male and female respondents.

Job satisfaction and the perception of fulfilled job expectations were significantly lower at T2 compared to T1 with a large effect size of 0.18 and 0.22 partial eta ${ }^{2}$ respectively (Table 2). The willingness of the respondents to choose

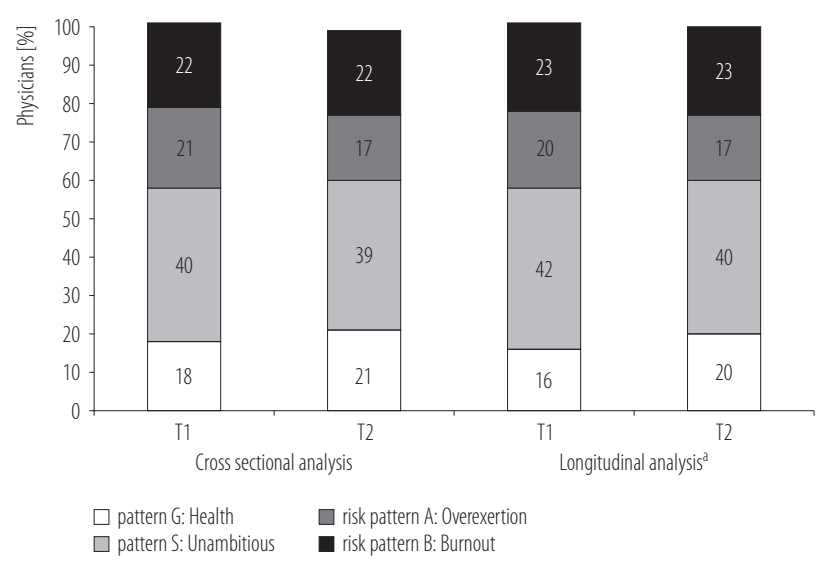

T1 - study in 2008; T2 - study in 2010.

${ }^{a}$ Physicians who responded at both measuring points.

Fig. 3. Work-related Behavior and Experience Patterns [23] of German physicians in private practice in Schleswig-Holstein

the profession again was stable, and there was no significant difference in their physical and mental health between $\mathrm{T} 1$ and $\mathrm{T} 2$.

At both $\mathrm{T} 1$ and $\mathrm{T} 2$, about $40 \%$ of physicians presented the unambitious pattern $\mathrm{S}$ characterized by low working motivation (Figure 3). One-fifth of physicians presented a pattern at risk for burnout (T1: $21.5 \%, \mathrm{~T} 2: 22.4 \%$ ) or overexertion (T1: 20.6\%, T2: 17\%). Another one-fifth presented a healthy pattern (T1: $18.3 \%, \mathrm{~T} 2: 21.4 \%$ ). Almost the same proportions were observed among those physicians who participated in both $\mathrm{T} 1$ and $\mathrm{T} 2(\mathrm{~N}=311)$;

Table 2. Development of work-related perceptions and quality of life of German physicians in private practice in Schleswig-Holstein between T1 (study in 2008) and T2 (study in 2010)

\begin{tabular}{lccrr}
\hline \multirow{2}{*}{$\begin{array}{c}\text { Work-related perception } \\
\text { and quality of life }\end{array}$} & \multicolumn{2}{c}{$\begin{array}{c}\text { Respondents' rating } \\
(\mathrm{M} \pm \mathrm{SD})\end{array}$} & $\mathrm{p}$ & Partial eta ${ }^{2}$ \\
\cline { 2 - 3 } & $\mathrm{T} 1$ & $\mathrm{~T} 2$ & $<0.001$ & 0.180 \\
\hline Job satisfaction & $3.07 \pm 0.97$ & $2.41 \pm 0.99$ & $<0.001$ & 0.215 \\
Fulfilled expectations & $3.44 \pm 0.91$ & $2.62 \pm 0.90$ & 0.737 & $<0.001$ \\
Study medicine again & $3.76 \pm 1.18$ & $3.78 \pm 1.26$ & 0.541 & 0.001 \\
Physical health & $51.84 \pm 6.60$ & $51.60 \pm 6.65$ & 0.982 & $<0.001$ \\
Mental health & $48.22 \pm 10.02$ & $48.23 \pm 9.78$ & & \\
\hline
\end{tabular}

Abbreviations as in Table 1. 


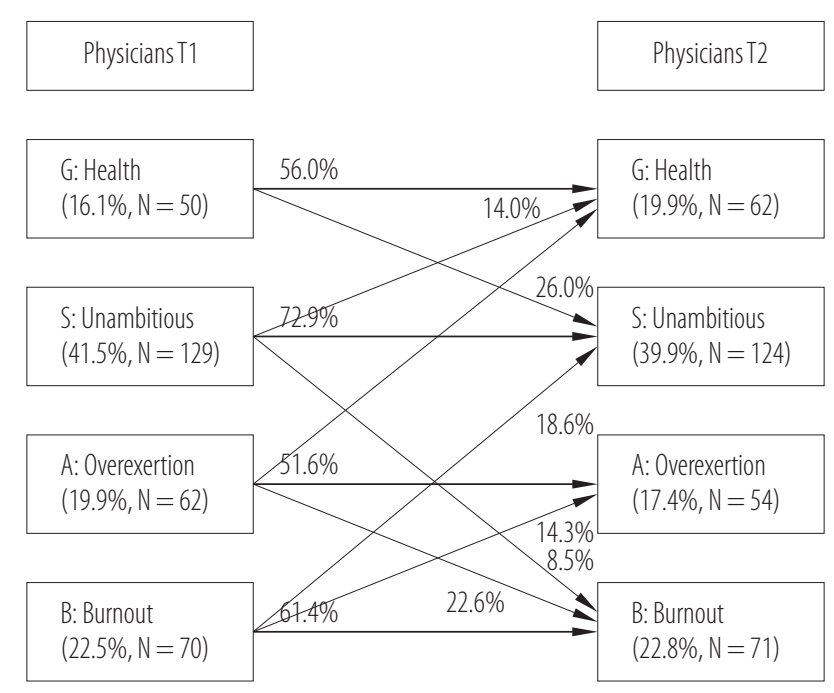

Percentages are presented only for the major pattern shifts, and therefore do not sum to $100 \%$.

Fig. 4. Pattern crossovers of German physicians in private practice in Schleswig-Holstein who responded at both T1 (study in 2008) and T2 (study in 2010) that is, there were no significant changes over the 2 time periods in the total distribution of those patterns.

Consistently, $72.9 \%$ of physicians who presented the unambitious pattern $\mathrm{S}$ and $61.4 \%$ with burnout-related risk pattern B at T1 stayed with this pattern at T2 (Figure 4). Less stable was the healthy pattern $\mathrm{G}(56 \%)$ and the pattern $\mathrm{A}$ at risk of overexertion (51.6\%). Substantial changes were seen from the pattern $\mathrm{G}$ to pattern $\mathrm{S}(26 \%)$ and from the risk pattern A to risk pattern $\mathrm{B}(22.6 \%)$. A high proportion also changed from $A$ to $G(19.4 \%)$ and from B to $S(18.6 \%)$.

Physicians with various work-related behavior and experience patterns rated the factors for or against the establishment of private practice significantly differently $(\mathrm{p}<0.05)$ (Table 3). Most significantly differing were responses from physicians who exhibited either the healthy pattern $\mathrm{G}$ or an unambitious pattern $\mathrm{S}$ vs. those who were at risk for overexertion (A) or burnout (B). For example,

Table 3. Differences in arguments (arranged in 5 factors) regarding establishment of private practice related to the behavior and experience patterns of German physicians in Schleswig-Holstein at T2 (study in 2010)

\begin{tabular}{|c|c|c|c|c|c|c|c|c|c|}
\hline \multirow{3}{*}{ Factor $^{\mathrm{a}}$ and argument } & \multicolumn{4}{|c|}{ AVEM patterns } & \multicolumn{4}{|c|}{ AVEM risk patterns } & \multirow{3}{*}{$\mathrm{p}^{*}$} \\
\hline & \multicolumn{2}{|c|}{ G: Health } & \multicolumn{2}{|c|}{ S: Unambitious } & \multicolumn{2}{|c|}{ A: Overexertion } & \multicolumn{2}{|c|}{ B: Burnout } & \\
\hline & $\mathrm{M}$ & SD & $\mathrm{M}$ & $\mathrm{SD}$ & $\mathrm{M}$ & SD & $\mathrm{M}$ & $\mathrm{SD}$ & \\
\hline I. Patient care & 1.6 & 0.7 & 1.6 & 0.7 & 1.9 & 0.7 & 2.1 & 0.8 & G-A, G-B, S-A, S-B \\
\hline variety of patient biographies & 1.6 & 0.8 & 1.6 & 0.8 & 2.0 & 0.8 & 2.1 & 0.9 & G-A, G-B, S-A, S-B \\
\hline broad case mix & 1.7 & 0.8 & 1.7 & 0.8 & 2.0 & 0.9 & 2.1 & 0.9 & G-B, S-A, S-B \\
\hline long-term care for patients & 1.5 & 0.7 & 1.6 & 0.8 & 1.9 & 0.9 & 2.0 & 0.9 & G-A, G-B, S-A, S-B \\
\hline continuity of physician-patient relationship & 1.5 & 0.7 & 1.5 & 0.7 & 1.7 & 0.8 & 2.0 & 0.9 & G-B, S-B, A-B \\
\hline variety of medical work & 1.7 & 0.8 & 1.8 & 0.9 & 2.1 & 1.0 & 2.3 & 1.0 & G-B, S-B \\
\hline II. Legislation and finances & 3.9 & 0.8 & 3.7 & 0.8 & 3.9 & 0.6 & 4.0 & 0.8 & S-B \\
\hline development of point-value & 4.2 & 0.9 & 4.0 & 1.0 & 4.3 & 0.9 & 4.4 & 0.9 & - \\
\hline real income & 3.6 & 1.3 & 3.4 & 1.2 & 3.7 & 1.1 & 4.0 & 1.1 & S-B \\
\hline financial risk & 3.7 & 1.1 & 3.5 & 1.1 & 3.8 & 0.9 & 4.1 & 0.9 & S-B \\
\hline development of health policy & 4.0 & 1.1 & 3.8 & 1.2 & 4.1 & 1.1 & 4.2 & 1.1 & - \\
\hline state regulation & 4.3 & 0.8 & 4.2 & 1.0 & 4.4 & 0.8 & 4.3 & 1.0 & - \\
\hline bank lending & 3.5 & 1.2 & 3.3 & 1.1 & 3.3 & 0.9 & 3.3 & 1.0 & - \\
\hline III. Work-organization and-development & 2.3 & 0.8 & 2.3 & 0.9 & 2.7 & 0.9 & 2.8 & 0.8 & G-A, G-B, S-A, S-B \\
\hline entrepreneurial freedom/autonomy & 2.1 & 1.1 & 2.2 & 1.2 & 2.5 & 1.2 & 2.6 & 1.3 & G-B \\
\hline flexible working hours & 2.1 & 1.1 & 2.0 & 1.0 & 2.6 & 1.1 & 2.6 & 1.1 & G-B, S-A, S-B \\
\hline professional development potentialities & 2.7 & 1.2 & 2.8 & 1.2 & 3.2 & 1.0 & 3.2 & 1.0 & G-B \\
\hline
\end{tabular}


Table 3. Differences in arguments (arranged in 5 factors) regarding establishment of private practice related to the behavior and experience patterns of German physicians in Schleswig-Holstein at T2 (study in 2010) - cont.

\begin{tabular}{|c|c|c|c|c|c|c|c|c|c|}
\hline \multirow{3}{*}{ Factor $^{\mathrm{a}}$ and argument } & \multicolumn{4}{|c|}{ AVEM patterns } & \multicolumn{4}{|c|}{ AVEM risk patterns } & \multirow{3}{*}{$\mathrm{p}^{*}$} \\
\hline & \multicolumn{2}{|c|}{ G: Health } & \multicolumn{2}{|c|}{ S: Unambitious } & \multicolumn{2}{|c|}{ A: Overexertion } & \multicolumn{2}{|c|}{ B: Burnout } & \\
\hline & $\mathrm{M}$ & SD & $\mathrm{M}$ & SD & $\mathrm{M}$ & $\mathrm{SD}$ & $\mathrm{M}$ & $\mathrm{SD}$ & \\
\hline IV. Special stressfactors & 3.6 & 0.7 & 3.4 & 0.7 & 3.7 & 0.6 & 3.7 & 0.6 & G-S, S-A, S-B \\
\hline proportion of simple medical cases & 3.2 & 1.0 & 3.1 & 0.9 & 3.3 & 0.9 & 3.1 & 0.9 & - \\
\hline time stress & 3.8 & 1.1 & 3.5 & 1.1 & 4.0 & 1.0 & 4.0 & 0.9 & S-A, S-B \\
\hline emotional strain & 3.2 & 1.0 & 2.9 & 1.0 & 3.3 & 0.9 & 3.5 & 0.9 & S-A, S-B \\
\hline administrative effort & 4.4 & 0.9 & 4.1 & 1.0 & 4.2 & 1.0 & 4.4 & 0.8 & - \\
\hline V. Significance of primary care & 2.9 & 0.8 & 2.9 & 0.8 & 3.1 & 0.8 & 3.2 & 0.7 & - \\
\hline significance of primary health care & 3.3 & 1.1 & 3.1 & 1.0 & 3.3 & 1.0 & 3.3 & 1.0 & - \\
\hline medical training & 2.8 & 0.9 & 3.0 & 0.9 & 3.1 & 0.9 & 3.1 & 0.9 & - \\
\hline prestige of primary health care & 2.6 & 1.2 & 2.6 & 1.1 & 3.1 & 1.0 & 3.1 & 1.1 & G-B, S-A, S-B \\
\hline
\end{tabular}

${ }^{\text {a }}$ Factor analysis with varimax rotation of the 22 items [10] regarding establishment of and work in private practice revealed a 5-factor model. AVEM (Arbeitsbezogenes Verhaltens- und Erlebensmuster) - Work-related Behavior and Experience Pattern [23].

Other abbreviations as in Table 1.

* Significance $\mathrm{p}<0.5$. Significant difference between patterns.

physicians presenting the $\mathrm{G}$ and $\mathrm{S}$ patterns rated variety of medical work, broad case mix, diverse patient biographies, and long-term care for patients - i.e., arguments that were summarized as the first factor (patient care) in the factor analysis - more positively than those at risk for burnout. For the items of factor 3 , differences could especially be seen between the healthy and the burnout-related pattern.

\section{DISCUSSION}

Over a 2-year observation period, job satisfaction and the feeling of satisified job expectations decreased among these physicians in Schleswig-Holstein, Germany. In contrast, their willingness to choose the profession once again remained unchanged. The fundamental issues of medical work, such as caring for diverse patients, and the continuity of physician-patient relationships remain strong arguments for physicians in favor of establishing and working in private practice. Arguments against the establishment of private practice were mainly contextual: state regulation, financial insecurity, health care policy and daily administrative responsibilities. Those opinions are very similar to those of a cohort of young Swiss physicians and German hematologists/oncologists in private practice, who also were drawn to patient care but saw its organization and regulation as disadvantageous [10,12].

\section{Attractiveness of establishing private practice}

Recent surveys of physicians in private practice in Germany show dissatisfaction with the amount of time spent on administrative matters [12,25]. They also point out the large proportion of physicians who are expected to retire [25], exacerbating existing shortages in rural areas, particularly (but not only) in the states of former East Germany. The perceptions of the physicians in our study sample may provide useful data to determine what could be done to entice German and other physicians to establish and to work in private practice. Beside administrative concerns, financial insecurity was one of the impeding factors voiced by physicians.

The 2 issues that were named as most important factors against establishing a private practice were: development of point-value and state regulation. In 1993, a significant health reform implemented fixed budgets for 
ambulatory fees of patients with statutory insurance in Germany. Services were no longer paid by a fixed price but doctors received points dependent on the complexity of the treatment. At the end of a quarterly period, a point-value was generated by dividing the fixed budget across the number of points. The result was a floating point-value and no certainty about quarterly income. In addition, a "treadmill effect" appeared, meaning that efforts to compensate low income by more services lead to a decrease in point-values and consequently to a further decrease in income. In a first legislative revision, fixed point budgets for each practice were introduced which somewhat stabilized the point-value but still caused services above this point budget to be reimbursed much less or not at all [26]. In the light of these findings, the top arguments against establishing private practice were comprehensible. In an attempt to address this, new regulations were introduced in Germany in January 2012, which guaranteed, for example, fixed prices, and put an end to decreasing point-values in rural areas. Another initiative allowed practices which were established with the financial responsibility vested in the local medical association to employ physicians who may later take over the responsibility of the practice themselves [3].

\section{Stress in private practice}

When asked directly, only a third of those physicians rated emotional strain as an argument against working in private practice. However, their mental health remained significantly worse than reference scores of the general population. The behavior and experience patterns revealed that a high proportion of those physicians were at risk for overexertion and burnout (together more than 40\%). Almost $10 \%$ of the "unambitious" physicians, and approximately $25 \%$ of those with the pattern at risk for overexertion surveyed in $\mathrm{T} 1$ experienced burnout by $\mathrm{T} 2$. The longitudinal analysis also revealed strong persistence of the unambitious pattern and the burnout-related risk pattern. This study therefore demonstrates that spontaneous recovery of burned out physicians is non-normative, without intervention. This notion is supported by studies conducted on medical students $[27,28]$ and other professional groups such as teachers [29].

An important question regarding the work-related behavior and experience patterns is whether these are only important for the physicians' health or if they also meaningfully affect patient care. Other study results have shown that physicians at risk for burnout have both lower job satisfaction as well as lower ambition for patient care [30,31]. While arguments with regard to legislation and finances (factor II) (Table 3) in our study have been rated almost unanimously against establishing and working in private practice irrespective of the individual behavior and experience pattern, physicians with the healthy pattern have rated the core issues of patient care (factor I) significantly higher in favor of private practice than those with a risk pattern for overexertion or burnout. This has also been true for the issues of work organization and development (factor III), which indicates that taking care of factors leading to a physician's overexertion or burnout could potentially improve their motivation for patient care and working quality in private practice. Unfortunately, Germany still lacks low threshold counseling services that are offered to physicians in need, such as by Villa Sana in Norway [32].

In addition education programs that promote not only the attractiveness of medical work in private practice but also outline how to manage and organize economic and administrative aspects of the business might encourage physicians to establish and work in private practice of their own $[10,33]$.

\section{Limitations}

This study surveyed a representative sample of physicians in private practice in one federal state of Germany. Consequently, the results may not be representative of all German physicians. The response rates for this study $(61 \%$ 
and $54 \%$ ) has been satisfactory, and favorably comparable with other large physician surveys; nonetheless, since only a good half of the consulted physicians have completed the survey, a non-response bias must be considered. Job satisfaction, willingness to study again and fulfilled job expectations have been measured by single-item questions. Though such an abbreviated assessment is common in scientific surveys, these results warrant further evaluation with more comprehensive instruments.

\section{CONCLUSIONS}

Those German physicians working in private practice perceive the fundamental aspects of the medical profession such as caring and interacting with patients as strong arguments in favor of establishing and working in private practice. However, constant legislative regulation and overwhelming administrative responsibilities promote job dissatisfaction. Although state regulation and administrative efforts have been consistently rated negatively by all physicians, those at risk for burnout have rated the tasks related to patient care much less positively than those with a healthy work-related behavior and experience pattern. Therefore, in order to improve patient care, foster physicians' job satisfaction, and improve their quality of life, attract physicians to work in private practice, and prevent physician undersupply (especially in rural areas), German physicians require a) improved legislation, b) the implementation of educational programs that promote the attractiveness of medical work in private practice and teach how to build, operate, manage and organize a business, and c) low threshold counseling services for the prevention of stress, overexertion and burnout.

\section{ACKNOWLEDGMENTS}

We thank the medical association of Schleswig-Holstein for their generous support of this study. We also thank Thomas Kötter, M.D., M.P.H. for his valuable comments and suggestions with respect to this manuscript.

\section{REFERENCES}

1. Clade H. [Family Physicians. Shortage increases]. Dtsch Arztebl In. 2014;111(7):258-9. German.

2. Kopetsch T. The migration of doctors to and from Germany. J Public Health. 2009;17:33-9, https://doi.org/10.1007/s10389008-0208-7.

3. Kassenärztliche Bundesvereinigung [Internet]. Berlin: KBV; 2014 [cited 2014 Feb 10]. [Shortage of Physicians]. Available from: http://www.kbv.de/html/themen_1076.php. German.

4. Hoppe JD. [Limitations to the physician's discretionary and therapeutic freedom and to the provision of health care for the general population by a shortage of financial and human resources - the rules of Section 2 Para. 1 and 4 of the Medical Professional Code of conduct and how much they are really worth]. Z Arztl Fortbild Qualitatssich. 2007;101(8):521-5, https://doi.org/10.1016/j.zgesun.2007.08.035. German.

5. Lisac M, Reimers L, Henke KD, Schlette S. Access and choice - Competition under the roof of solidarity in German health care: An analysis of health policy reforms since 2004. Health Econ Policy Law. 2010;5(Pt 1):31-52, https://doi.org/ 10.1017/S1744133109990144.

6. Stock SA, Redaelli M, Lauterbach KW. Disease management and health care reforms in Germany - Does more competition lead to less solidarity? Health Policy. 2007;80(1):86-96, https://doi.org/10.1016/j.healthpol.2006.02.005.

7. Scheffler A. [Dealing with bottlenecks in ambulatory patient care: Experiences of an office-based Statutory Health Insurance physician]. Z Evid Fortbild Qual Gesundhwes. 2010;104(5): 372-4, https://doi.org/10.1016/j.zefq.2010.06.007. German.

8. Natanzon I, Ose D, Szecsenyi J, Joos S. [What factors aid in the recruitment of general practice as a career? An enquiry by interview of general practitioners]. Dtsch Med Wochenschr. 2010;135(20):1011-5, https://doi.org/10. 1055/s-0030-1253690. German.

9. McKinlay JB, Marceau L. New wine in an old bottle: Does alienation provide an explanation of the origins of physician discontent? Int J Health Serv. 2011;41(2):301-35, https://doi. org/10.2190/HS.41.2.g. 
10. Buddeberg-Fischer B, Stamm M, Buddeberg C, Klaghofer R. [Young physicians' view on factors that increase the attractiveness of general practice]. Gesundheitswesen. 2008;70(3):123-8, https://doi.org/10.1055/s-2008-1062721. German.

11. Götz K, Broge B, Willms S, Joos S, Szecsenyi J. [Job satisfaction of general practitioners]. Med Klin. 2010;105(11):76771, https://doi.org/10.1007/s00063-010-8881-z. German.

12. Ansmann L, Nitzsche A, Neumann M. [Haematologists and Oncologists in private practice: stressed but mostly satisfied]. Dtsch Arztebl Int. 2014;111(7):262-4. German.

13. Siegrist J, Shackelton R, Link C, Marceau L, von dem Knesebeck O, McKinlay J. Work stress of primary care physicians in the US, UK and German health care systems. Soc Sci Med. 2010;71(2):298-304, https://doi.org/10.1016/j.socscimed.2010.03.043.

14. Voltmer E, Rosta J, Siegrist J, Aasland OG. Job stress and job satisfaction of physicians in private practice: Comparison of German and Norwegian physicians. Int Arch Occup Environ Health. 2012;85(7):819-28, https://doi.org/10.1007/ s00420-011-0725-5.

15. Voltmer E, Schwappach DLB, Frank E, Wirsching M, Spahn C. Work-related behavior and experience patterns and predictors of mental health in German physicians in medical practice. Fam Med. 2010;42(6):433-9.

16. Wörz M, Busse R. Analysing the impact of health-care system change in the EU member states - Germany. Health Econ. 2005;14(S1):S133-49, https://doi.org/10.1002/hec.1032.

17. Kroneman MW, Van der Zee J, Groot W. Income development of General Practitioners in eight European countries from 1975 to 2005. BMC Health Serv Res. 2009;9:26, https:// doi.org/10.1186/1472-6963-9-26.

18. Kern T, Kohnen T. [Healthcare system and aspects of healthcare economics. Sector ophthalmology - Part 2: Outpatient care].Ophthalmologe.2010;107(12):1185-91, https://doi.org/ 10.1007/s00347-010-2267-8. German.

19. Ware J Jr., Kosinski M, Keller SD. A 12-Item Short-Form Health Survey: Construction of scales and preliminary tests of reliability and validity. Med Care. 1996;34(3):220-33, https://doi.org/10.1097/00005650-199603000-00003.

20. Gandek B, Ware JE, Aaronson NK, Apolone G, Bjorner JB, Brazier JE, et al. Cross-validation of item selection and scoring for the SF-12 Health Survey in nine countries: Results from the IQOLA Project. J Clin Epidemiol. 1998;51(11):1171-8, https://doi.org/10.1016/S0895-43 56(98)00109-7.

21. Kudielka BM, Hanebuth D, von Kanel R, Gander ML, Grande G, Fischer JE. Health-related quality of life measured by the SF12 in working populations: Associations with psychosocial work characteristics. J Occup Health Psychol. 2005; 10(4):429-40, https://doi.org/10.1037/1076-8998.10.4.429.

22. Ware JE, Kosinski M, Keller SD. SF-36 physical and mental health summary scales: A user's manual. Boston: The Health Institute, New England Medical Center; 1994.

23. Schaarschmidt U, Fischer AW. [Work-related behaviour and experience pattern]. Frankfurt a. M.: Swets \& Zeitlinger; 2008. German.

24. Friedman M, Rosenmann RH. Type A behavior and your heart. New York: Knopf; 1974.

25. Rieser S. [Physician monitoring: Satisfied - however, there is a lack of time]. Dtsch Arztebl Int. 2014;111(29-30):1278-9. German.

26. Schmitz H. Practice budgets and the patient mix of physicians - The effect of a remuneration system reform on health care utilisation. J Health Econ. 2013;32(6):1240-9, https://doi.org/10.1016/j.jhealeco.2013.09.013.

27. Dyrbye LN, Thomas MR, Massie FS, Power DV, Eacker A, Harper W, et al. Burnout and suicidal ideation among U.S. medical students. Ann Intern Med. 2008;149(5):334-41, https://doi.org/10.7326/0003-4819-149-5-200809020-00008.

28. Voltmer E, Aasland OG, Rosta J, Spahn C. Study-related health and behavior patterns of medical students: A longitudinal study. Med Teach. 2010;32(10):e422-8 https://doi.org/ 10.3109/0142159X.2010.496008.

29. Kieschke U, Schaarschmidt U. Professional commitment and health among teachers in Germany. A typological ap- 
proach. Learn Instr. 2008;18(5):429-37, https://doi.org/10.1016/ j.learninstruc.2008.06.005.

30. Renzi C, Tabolli S, Ianni A, Di Pietro C, Puddu P. Burnout and job satisfaction comparing healthcare staff of a dermatological hospital and a general hospital. J Eur Acad Dermatol Venereol. 2005;19(2):153-7, https://doi.org/10.1111/j.14 68-3083.2005.01029.x.

31. Williams ES, Manwell LB, Konrad TR, Linzer M. The relationship of organizational culture, stress, satisfaction, and burnout with physician-reported error and suboptimal patient care: Results from the MEMO study. Health Care
Manage Rev. 2007;32(3):203-12, https://doi.org/10.1097/01. HMR.0000281626.28363.59.

32. Ro KEI, Gude T, Tyssen R, Aasland OG. Counselling for burnout in Norwegian doctors: One year cohort study. BMJ. 2008;337:a2004, https://doi.org/10.1136/bmj.a2004.

33. Jungbauer J, Kamenik C, Alfermann D, Braehler E. [How do young physicians assess their medical studies in retrospect? Results of a medical graduates' survey in Germany]. Gesundheitswesen. 2004;66(1):51-6, https://doi.org/10.1055/ s-2004-812705. German.

This work is available in Open Access model and licensed under a Creative Commons Attribution-NonCommercial 3.0 Poland License - http://creativecommons.org/ licenses/by-nc/3.0/pl/deed.en. 